\title{
A CAMINHADA CRISTÃ: TRADUÇÕES DE METÁFORAS EM O PEREGRINO
}

\author{
ADAURI BREZOLIN* \\ PRISCILA KLEIN CARDOSO*
}

\begin{abstract}
RESUMO
A alegoria cristã, O Peregrino (em inglês, The Pilgrim's Progress), de John Bunyan (1678), considerada uma das obras mais significativas da literatura inglesa, foi de grande importância para a formação dos cristãos. Desde sua publicação, vem sendo traduzida para várias línguas com propósitos de evangelização. Esta análise comparativa de metáforas a partir das traduções para português brasileiro de Robert Kalley (1856) e de Eduardo Ferreira (2006) objetiva verificar como cada tradutor lidou com essa figura de linguagem, amplamente empregada na obra. Após cotejo entre os textos, excertos com esse recurso expressivo foram selecionados e analisados segundo a teoria de metáfora conceptual (LAKOFF \& JOHNSON, 2003) e equivalência pragmática na tradução (BAKER, 2001). Os resultados revelam as diferentes soluções dadas por cada tradutor: manutenção total, manutenção parcial e/ou omissão das metáforas. Palavras-chave: O Peregrino; tradução de metáforas; equivalência pragmática.
\end{abstract}

\section{ABSTRACT}

The Christian allegory, The Pilgrim's Progress, by John Bunyan (1678), regarded as one of the most significant works in the English literature, has been used by Christians for evangelization purposes. Since its publication, it has been translated into

Universidade Metodista de São Paulo

Cadernos de Educação, v.18, n. 36, jan.-jun. 2019 
several languages. This article presents a comparative analysis of metaphors from two translations into Brazilian Portuguese, Robert Kalley's (1856) and Eduardo Ferreira's (2006), aiming to verify how each translator treated this figure of speech, widely used in the book. After comparing the texts, excerpts with such expressive resource were selected and analyzed in the light of conceptual metaphor theory (LAKOFF \& JOHNSON, 2003), and pragmatic equivalence in translation (BAKER, 2001). The results reveal different solutions offered by each translator: total maintenance, partial maintenance and/or omission of metaphors.

Keywords: The Pilgrim's Progress; translation of metaphors; pragmatic equivalence.

\section{INTRODUÇÃO}

A obra The Pilgrim's progress ${ }^{1}$, de John Bunyan (1678), foi basilar na formação dos cristãos entre os séculos XVII e XIX. Quatorze anos após a primeira edição, já haviam sido impressas 100 mil cópias - número surpreendente à época. Segundo o historiador Latourette (2006), é uma das obras mais lidas em seu original e mais traduzidas para muitas línguas, o que tornou comum sua divulgação nos processos de evangelização. Os primeiros missionários vindos ao Brasil, no século XIX, trouxeram a prática da leitura literária aos novos convertidos, aproveitando-se da admiração de livros estrangeiros (LEONEL, 2000).

A primeira tradução de The Pilgrim's Progress em língua portuguesa, A viagem do Christão para a Bemaventurança Eterna, foi realizada em 1856, por Robert Reid Kalley (1809-1888), médico-missionário escocês e o pioneiro de missão no Brasil. Vendo nos jornais a oportunidade de divulgação do evangelho, Kalley publica a tradução no periódico Correio Mercantil (CARDOSO, 2001). Nos anos seguintes e por intermédio de outros missionários, "O Peregrino", assim chamado, era vendido junto com a

Título pelo qual a obra é comumente catalogada, embora também possa ser encontrada como The Pilgrim's Progress from This World, to That Which Is to Come: Delivered under the Similitude of a Dream. 
Bíblia, servindo-lhe de apoio, uma vez que continha versos que faziam referência ao livro sagrado. Assim, Leonel (2000, p. 59) afirma que, no Brasil, a obra não formava o leitor protestante, mas participava da “instituição desse leitor 'como' protestante". Em virtude da importância da obra no contexto religioso e de nosso interesse em tradução, surgiu a ideia de analisar duas traduções para o português brasileiro a partir de determinadas inconsistências observadas, sobretudo, no campo metafórico, visto que a obra é uma alegoria da vida cristã.

No trabalho resultante (CARDOSO, 2016), por meio do cotejo do texto de partida, The Pilgrim's progress, de John Bunyan (1678); da primeira tradução, A viagem do Christão para a Bemaventurança Eterna, de Robert Kalley (1856), e da segunda, O Peregrino, de Eduardo Ferreira (2006), realizou-se uma análise comparativa sobre como diferentes leituras, por parte de cada tradutor, podem resultar em textos com diferentes implicaturas daquelas propostas pelo autor no tangente ao tratamento dado às metáforas.

Neste artigo, pretendemos apresentar e comentar quatro excertos representativos das distintas maneiras de como os tradutores transpuseram as metáforas para a língua de chegada. Os trechos selecionados para tal propósito serão expostos em tabelas, em que se comparam as metáforas e seus contextos, na língua de partida, bem como as respectivas traduções, seguidas de comentários e considerações sobre cada opção tradutória. Para tanto, esta análise fundamenta-se na teoria de metáfora conceptual (LAKOFF \& JOHNSON, 2003) e na teoria tradutória de equivalência pragmática (BAKER, 2001). Como veremos em nossos resultados, em alguns casos houve manutenção total de metáfora (mantendo-se, assim, expressão e sentido metafóricos semelhantes ao da língua de partida); em outros, houve manutenção parcial de metáfora (negligenciando-se ora o sentido metafórico, ora a expressão metafórica); e um caso de omissão de metáfora.

Antes, porém, de iniciarmos nossas análises, apresentaremos breves considerações sobre alegoria, metáfora conceptual e equivalência pragmática. 


\section{UMA ALEGORIA CRISTÃ}

Em primeiro lugar, é importante lembrarmos que "O Peregrino" emprega a alegoria como recurso retórico. Já chamada de "significações secretas", alegoria consiste num discurso que "faz entender outro ou alude a outro, que fala de uma coisa referindo-se a outra. (...) Empregando imagens, figuras, pessoas, animais, o primeiro discurso concretiza as ideias, qualidades ou entidades abstratas que compõem o outro" (MOISÉS, 2004, p. 14), ou seja, é um enredo que, por meio de metáforas, adquire novo significado. Como exemplo, podemos citar contos ou crônicas infantis, como O Patinho Feio, de Hans Christian Andersen, em que podemos ressignificar a ideia de alguém que não consegue encontrar seu próprio lugar no mundo; ou As Crônicas de Nárnia, de C. S. Lewis, em que um reino distante da nossa realidade é governado por um leão que oferece sua vida em favor de seus súditos (lembrando o sacrifício de Jesus Cristo).

A obra alegórica analisada neste trabalho narra a história de um homem chamado Cristão, o qual descobre, por meio de um livro (a Bíblia), que sua cidade será destruída e, com essa descoberta, um grande fardo recai sobre suas costas. Atormentado, ele segue por um caminho que promete salvar a si mesmo e à sua família - ainda que essa lhe desacredite. Nesse caminho ele se depara com tentações (de atalhos a riquezas materiais), desafios e lutas (espirituais e literais) com outros e consigo mesmo, tudo isso para alcançar a Cidade Celestial, onde se diz não haver nunca mais dores ou tristezas.

Acreditamos que, por meio dessa alegoria, John Bunyan consegue, ou, pelo menos, tenta levar o leitor (seguidor de Cristo) a refletir sobre sua vida terrena, com problemas e dificuldades. Todas as situações, simbolizadas pela própria jornada de Cristão, são apresentadas sob a forma de metáforas.

\section{METÁFORA CONCEPTUAL}

Os linguistas e teóricos George Lakoff e Mark Johnson entendem que a metáfora é cognitiva, ou seja, não se limita à linguagem, mas está também no próprio pensamento e na ação dos falantes de uma língua: “(n)osso sistema conceitual comum, 
em termos de pensamento e ação, é fundamentalmente metafórico em natureza"2 (LAKOFF; JOHNSON, 2003, p. 3, tradução nossa). Isso significa que um conceito metafórico pode já estar retratado na forma como a pessoa lida com aquela metáfora, como veremos a seguir.

Para esclarecer como um conceito pode ser metafórico, os autores dão o exemplo da metáfora conceptual ARGUMENTO É GUERRA ${ }^{34}$ (LAKOFF; JOHNSON, 2003, p. 4). Várias expressões metafóricas são usadas diariamente representando essa metáfora. Por exemplo, quando dizemos "ganhamos, perdemos, atacamos, defendemos, rebatemos um argumento", estamos estruturando nosso discurso remetendo-o ao conceito de guerra. Um importante fator apontado por esses autores é a questão cultural. A título de exemplificação, na cultura americana, debates são estruturados com o conceito de guerra, da mesma maneira que são na cultura brasileira; portanto, tornam-se fáceis a associação e o entendimento da metáfora ARGUMENTO É GUERRA para brasileiros. Outras culturas, porém, podem estruturar debates de modo distinto, o que modificaria a forma como as pessoas se expressam e, consequentemente, como se relacionam com os conceitos envolvidos.

Lakoff e Johnson (2003) apresentam quatro tipos de metáforas: as estruturais, as orientacionais, as ontológicas e as de personificação. As metáforas estruturais são as que guiam toda a teoria, "(c)asos em que um conceito é estruturado metaforicamente em termos de outro"5 (p. 14), como AMOR É UMA JORNADA ${ }^{6}$, em que usamos expressões como "o relacionamen-

2 Todas as citações originadas em língua inglesa são tradução nossa para o português. "Our ordinary conceptual system, in terms of which we both think and act, is fundamentally metaphorical in nature". (LAKOFF; JOHNSON, 2003, p. 3)

3 "ARGUMENT IS WAR".

4 Usa-se caixa alta para metáforas conceptuais.

5 "Cases where one concept is metaphorically structured in terms of another". (LAKOFF; JOHNSON, 2003, p. 14)

6 "LOVE IS A JOURNEY". 
to não está indo a lugar algum"7 (LAKOFF; JOHNSON, 2003, p. 45). As metáforas orientacionais são aquelas em que o sistema de conceitos diz respeito um ao outro usando direções, como PARA CIMA - PARA BAIXO ${ }^{8}$, em que temos FELIZ É PARA CIMA ("comigo está tudo em cima hoje") (LAKOFF; JOHNSON, 2003, p. 10). Metáforas ontológicas são as experiências que vemos como entidades ou substâncias, por exemplo, INFLAÇÃO É UMA ENTIDADE ${ }^{10}$ (LAKOFF; JOHNSON, 2003,p. 26), pois dessa forma elas podem ser categorizadas, agrupadas, quantificadas, e assim por diante, como "inflação baixa/alta" (LAKOFF; JOHNSON, 2003, p. 26) ou "comprar terreno é a melhor forma de lidar com a inflação"12 (LAKOFF; JOHNSON, 2003, p. 26). Metáforas de personificação são aquelas em que a entidade é tratada como pessoa. No exemplo de INFLAÇÃO É UMA ENTIDADE, temos "a inflação está reduzindo nosso padrão de vida"13 (LAKOFF; JOHNSON, 2003, p. 26), ou seja, a metáfora tratada como pessoa, possui características e atividades humanas.

Nos excertos escolhidos para a análise é possível observar metáforas estruturais e ontológicas.

\section{CRISTALIZAÇÃO DA METÁFORA}

Quando uma metáfora é usada repetidamente por um longo período de tempo, a ponto de ser absorvida pela língua, dizemos que ela é cristalizada, consagrada. Isso ocorre com metáforas que "perderam seu caráter inovador, original e transformaram-se numa metáfora comum, morta, que não mais causa estranheza. Em outras palavras, transformaram-se numa catacrese" (SÉR-

\footnotetext{
7 "The relationship is going nowhere". (LAKOFF; JOHNSON, 2003, p. 45) 8 "UP-DOWN".

9 “HAPPY IS UP” (I'm feeling up today). (LAKOFF; JOHNSON, 2003, p. 10)

10 "INFLATION IS AN ENTITY".

11 "Low/high inflation". (LAKOFF; JOHNSON, 2003, p. 26)

12 "Buying land is the best way of dealing with inflation". (LAKOFF; JOHNSON, 2003, p. 26)

13 "Inflation is lowering our standard of living". (LAKOFF; JOHNSON, 2003, p. 26)
} 
GIO, 2013). Os falantes da língua já não percebem que essas expressões são metafóricas, pois estão desgastadas pelo uso. Isso leva muitos estudiosos a crer que já não se trata de metáforas. Entretanto, acreditamos que essas expressões continuam pertencendo à mesma categoria, apesar do tempo decorrido e da falta de percepção dos falantes da língua.

\section{EQUIVALÊNCIA PRAGMÁTICA: IMPLICATURA}

Pragmática, estudo da língua em uso, destina-se à análise do sentido transmitido e manipulado pelos participantes em uma situação comunicativa (BAKER, 2001). Essa autora apresenta duas noções na esfera da pragmática: coerência e implicatura, as quais podem ser aplicadas à tradução.

A coerência existe quando o leitor entende o texto, quando ele faz sentido. Entretanto, a coerência de um texto existe dependendo apenas do leitor e de seu conhecimento de mundo (BAKER, 2001), da "bagagem" que acumula com o decorrer dos anos. O mesmo acontece com o tradutor:

Um tradutor deve considerar a gama de conhecimento disponível a seus leitores da língua de chegada e das expectativas que eles provavelmente terão sobre coisas como a organização do mundo, a organização de língua de forma geral, a organização e convenção de certos tipos de textos, a estrutura de relações sociais, e adequações ou inadequações de certos tipos de comportamentos linguísticos e não-linguísticos, entre outras coisas ${ }^{14}$. (BAKER, 2001, p. 222)

Tendo em vista que o tradutor é, antes de tudo, leitor, cabe a ele, a partir de sua leitura, associar toda a organização de mundo e língua do texto de partida para gerar uma tradução

14 "A translator has to take account of the range of knowledge available to his/her target readers and of the expectations they are likely to have about such things as the organization of the world, the organization of language in general, the organization and conventions of particular text types, the structure of social relations, and the appropriateness or inappropriateness of certain kinds of linguistic and non-linguistic behaviour, among other things". (BAKER, 2001, p. 222) 
que consiga, de igual modo, alcançar o público da língua de chegada, levando em conta as características de sua cultura.

Implicatura refere-se ao que o falante quer dizer ou insinua, mas não diz literalmente (GRICE, 1975 apud BAKER, 2001). Diante do exemplo: "P: Quer dar uma volta?” - "R: Está chovendo", como é possível saber o que a resposta à pergunta quis insinuar? Apenas ao procurar interpretações do que não foi dito, o que está nas entrelinhas do contexto da situação, pode-se chegar à coerência de diálogos como o exemplificado. Ao responder "Está chovendo", o interlocutor insinua que sua resposta tende a uma negativa, ou seja, que "não quer dar uma volta".

Implicaturas podem dificultar o trabalho do tradutor. Durante o processo tradutório, ele pode consciente ou inconscientemente eliminar aspectos da frase que possam originar mais interpretações, "Ela/ele pode até, inadvertidamente, dar margem a outras interpretações que não sejam derivadas do texto original"15 (BAKER, 2001, p. 228). Baker nos alerta sobre alguns aspectos da prática tradutória. Primeiro, destaca que é imprescindível a compreensão do significado das palavras e estruturas da língua para que possa ser traduzido adequadamente para a língua de chegada. É necessário conhecer os padrões em que as implicaturas são transmitidas em cada língua. "Surgem problemas na tradução quando as funções de tais padrões não são reconhecidas e uma forma literal ou quase literal de transferência distorce a implicatura original ou transmite uma diferente"16 (BAKER, 2001, p. 230).

Da mesma forma, a autora ressalta a importância de o tradutor conhecer referências, devendo, entretanto, atentar-se à história, às características físicas e sociais e ao contexto em questão para que seja feita uma transferência apropriada e para que o leitor não se confunda, chegando, assim, a algo coerente

15 "S/he may even inadvertently give rise to other interpretations which are not derivable from the original text". (BAKER, 2001, p. 228)

16 "Problems arise in translation when the function of such patterns is not recognized and a literal or near-literal transfer of form distorts the original implicature or conveys a different one". (BAKER, 2001, p. 230) 
(BAKER, 2001). Baker também afirma que o contexto deve ser transmitido de forma adequada para a língua de chegada; caso contrário, o leitor poderá não alcançar as devidas implicaturas propostas pelo original.

Deve-se ter em mente que mesmo frases com implicaturas, ou seja, aquelas em que há margem para mais de uma interpretação, precisam estar estruturadas de forma coerente para o leitor, para que o objetivo da comunicação seja alcançado. Algo importante de se conhecer antes de traduzir é o entendimento de mundo da cultura de chegada. Como, às vezes, um livro de outra cultura pode chocar o leitor da cultura de chegada, caberá ao tradutor "alertá-lo" sobre algo que necessite de esclarecimentos em prefácios ou notas explicativas.

Feitas essas considerações introdutórias e teóricas, passemos às análises.

\section{ANÁLISE COMPARATIVA}

Em muitos momentos, John Bunyan cita referências bíblicas para que o leitor entenda de onde vem tal figura de linguagem. Assim, recorremos à Bíblia para melhor entendimento e interpretação das metáforas provenientes dela, e também para verificação de como essas metáforas foram passadas nas traduções para a língua portuguesa. Ao conferir os versículos presentes em cada trecho, nossa leitura nos leva a crer que as seguintes versões bíblicas foram usadas: Autorizada King James ${ }^{17}$, versão antiga na língua inglesa, originada em 1611, usada por John Bunyan; versão em português europeu, por Antonio Pereira de Figueiredo, usada por Robert Kalley; e a versão Almeida Revista e Atualizada, usada por Eduardo Ferreira.

A seguir, analisamos os excertos em que os termos motivadores das metáforas aparecerem.

17 BÍBLIA ONLINE. Disponível em: < https://www.bibliaonline.com.br/ akjv>. Acesso em: 14 out. 2016. 
Tabela 1 - "Peregrino" - termo motivador da metáfora

\begin{tabular}{c}
\hline Original \\
\hline The Pilgrim's progress \\
\hline Tradução 1856 \\
\hline A Viagem do Christão Para a Bemaveunturança Eterna \\
Tradução 2006 \\
\hline O Peregrino \\
\hline
\end{tabular}

Fonte: Autores (2016)

Encontramos metáfora já no título do livro. A imagem de "peregrino" é há muito recorrente, inclusive nos textos bíblicos e, por conseguinte, na cultura cristã. Faz parte da metáfora estrutural VIDA É UMA JORNADA (LAKOFF; JOHNSON, 2003), em que as pessoas são peregrinas, passageiras na vida. $\mathrm{Na}$ leitura bíblica pode-se ver, no Antigo Testamento, o povo hebreu migrar algumas vezes a fim de encontrar um novo lar (seja por conflitos contra outros povos ou a mando de Deus); já no Novo Testamento, vemos a associação de tal imagem como metafórica: "[...] confessaram que eram estrangeiros e peregrinos na terra. Porque, os que isto dizem, claramente mostram que buscam uma pátria. [...] Mas agora desejam uma melhor, isto é, a celestial" (Hb. 11: 13c-14, 16a), ou seja, são "peregrinos" na Terra, pois seu "lar" é juntamente a Deus (seja "céu”, "eternidade" ou outra nomenclatura).

De acordo com de Lange, a metáfora VIDA É UMA VIAGEM tem uma interpretação religiosa, “(o) fenômeno da peregrinação é quase tão velho quanto a humanidade. Quase todas as tradições religiosas encontram o sagrado em algum lugar, e celebram movimentos para, de e ao redor de tal local" (DE LANGE, 2004, p. 97) ${ }^{18}$. De Lange aponta duas formas de se entender a jornada da peregrinação: uma é o sentido "não-

\footnotetext{
18 "The pilgrimage phenomenon is almost as old as humanity. Almost all religious traditions find the sacred in some place and celebrate movements to, from, and around this place". (DE LANGE, 2004, p. 97)
} 
-metafórico", em que o peregrino parte da casa terrena para visitar um destino sagrado; a outra, o sentido metafórico, em que o peregrino leva uma vida voltada à vida espiritual.

Tendo em vista esses fatores, podemos afirmar que a tradução de Robert Kalley (1856) mantém a origem da metáfora - vida como viagem, mas não utiliza a mesma expressão metafórica de "peregrino", não mantendo, assim, a metáfora do título. Diferentemente, Eduardo Ferreira, tradutor da edição de 2006, mantém a metáfora em palavra e sentido, ainda que não tenha usado a palavra "progresso". A metáfora "peregrino", como mencionamos, já está consagrada, uma vez que é utilizada desde, pelo menos, os escritos bíblicos. Dessa forma, temos aqui uma catacrese - expressão cristalizada pelo tempo.

Tabela 2 - "Fardo" - termo motivador da metáfora

\section{Original}

I dreamed, and behold I saw a man clothed with rags, standing in a certain place, with his face from his own house, a book in his hand, and a great burden upon his back (Isa. lxiv. 6; Luke xiv. 33; Ps. xxxviii. 4; Hab. ii. 2; Acts xvi. 31). (p. 7)

Tradução 1856

[...] e estando a dormir vi, em sonhos, um homem vestido com $(a)^{1}$ trapos sujos e rotos. Elle estava em pé, com as costas voltadas para a sua casa; tinha um $(b)^{2}$ livro na mão, e estava $(c)^{3}$ carregado com um fardo mui pesado. (Ed. 274)

${ }^{1}$ Seus merecimentos. (Isaías 616)

${ }^{2}$ Sua consciencia

${ }^{3}$ Salmo 375

Tradução 2006

Vi um homem vestido de trapos (Is 64:6), de pé em determinado lugar, com o rosto voltado para o lado oposto da própria casa, um livro na mão e um grande fardo às costas (Sl 38:4). (p.21)

Fonte: Autores (2016) 
Nesse excerto surge a primeira aparição de referências bíblicas, a nosso ver, cuidado de Bunyan para com seus leitores, ou um traço da tradição em textos puritanos, para que soubessem de onde vinham suas referências e ideias para a obra. A metáfora em questão é colocada como algo literal no livro - sendo, inclusive, referência de imagens sobre o livro. Tendo em vista que se trata de alegoria, como já citado aqui, voltamo-nos ao Salmo 38, mencionado no original para saber sua origem, a começar do final do verso 3: “[...] não há saúde nos meus ossos, por causa do meu pecado. Pois já se elevam acima de minha cabeça as minhas iniquidades; como fardos pesados, excedem as minhas forças". É clara a comparação feita pelo salmista e, de igual modo, Bunyan a usa. A sequência do texto é: ele carregava um livro e então aparece o fardo em suas costas. Podemos supor, com essa narrativa e com o salmo, que é quando ele entende seus erros e iniquidades à luz da Bíblia, que o fardo aparece. Dessa forma, podemos dizer que a metáfora, ontológica (LAKOFF; JOHNSON, 2003), é: INIQUIDADE É FARDO.

Em ambas as traduções, "burden" é traduzido como "fardo". Na primeira tradução há notas (interpretativas) do tradutor, além de ser usada outra referência bíblica (Salmo 37:5). De acordo com Baker (2001), essa alteração de aspectos da frase (ainda que com notas e não diretamente no texto) podem originar outras interpretações por parte do leitor, não as que Bunyan desejava. Não temos como justificar as interpretações de Kalley, uma vez que o texto e as referências bíblicas não dão margem a tais alegações. Quanto às referências, podemos supor que o tradutor de 1856, conhecedor bíblico, acreditou serem textos mais próximos ou compreensíveis aos seus leitores. Entretanto, desse modo, o significado da metáfora não é mantido, ainda que seja usada a palavra "fardo".

$\mathrm{Na}$ tradução de 2006 não encontramos todas as referências do original, mas, em contrapartida, o verso explicativo para a metáfora em análise - usado pelo autor - é citado entre parên- 
teses. Dessa forma, como visto em Baker (2001), ainda que o leitor não seja conhecedor bíblico, verificando o versículo ele pode chegar ao entendimento da metáfora, chegando à coerência. Nesse caso, a metáfora é mantida - palavra e interpretação.

Tabela 3 - "Muralha/muro" - termos motivadores da metáfora

\begin{tabular}{|c|}
\hline Original \\
\hline $\begin{array}{l}\text { Now I saw in my dream, that the highway up which Christian was to go, } \\
\text { was fenced on either side with a wall, and that wall was called Salvation. } \\
\text { (Isa. xxvi. i.) (p. 42) }\end{array}$ \\
\hline Tradução 1856 \\
\hline $\begin{array}{l}\text { Vi em meu sonho que em cada lado do caminho em que Christão andava } \\
\text { havia uma muralha que se chama Salvação [...] (Ed. 283) }\end{array}$ \\
\hline Tradução 2006 \\
\hline $\begin{array}{l}\text { Em meu sonho vi que a estrada pela qual Cristão havia de seguir era } \\
\text { murada dos dois lados, e o muro chamava-se Salvação. (p. 59) }\end{array}$ \\
\hline
\end{tabular}

Fonte: Autores (2016)

\section{O protestantismo acredita que}

quando Deus criou o homem ele entrou em uma aliança com este na qual, seguindo o caminho da obediência, o homem poderia então se elevar a um estado confirmado de santidade; ao passo que, se escolhesse desobedecer, cairia então sob a escravidão do pecado. (TENNEY, 2008, p. 396-397) ${ }^{19}$.

Assim, quando o homem desobedece a Deus (Gênesis 2), se inicia o conceito (e a necessidade) de salvação - obter, de alguma forma, a libertação da vida que distancia a pessoa de Deus da vida escrava do pecado; ou seja, alcançar essa salvação significa estar novamente em união e em paz com Deus, sob Sua proteção.

19 SALVAÇÃO. In: Enciclopédia da Bíblia. 1 ed. São Paulo: Cultura Cristã, 2008. (Volume 5). 
O versículo indicado no original segue: "Naquele dia, se entoará este cântico na terra de Judá: Temos uma cidade forte; Deus lhe põe a salvação por muros e baluartes". Nos tempos bíblicos, a melhor e mais eficiente forma de se proteger contra invasores, além de um bom exército, era com muralhas nos limites da cidade. Ao ler o trecho e associá-lo ao verso, podemos dizer que Bunyan usa a metáfora ontológica SALVAÇÃO É PROTEÇÃO, uma vez que a representa como um "muro". Desse modo, ao receber a salvação ${ }^{20}$, o cristão se sente seguro com Deus, tal qual o profeta Isaías descreve sobre o morador da "cidade forte".

Embora os tradutores tenham optado por palavras diferentes, "muralha" e "muro", elas têm o valor semântico próximo, não alterando o entendimento do leitor. Entretanto, nenhum dos tradutores acrescentou a indicação do versículo em seus textos; o que que pode alterar a implicatura do leitor brasileiro (BAKER, 2001). Ainda que entenda que esteja lendo uma metáfora, o leitor pode não chegar ao entendimento proposto por Bunyan.

Dessa forma, segundo nossa interpretação, a metáfora SALVAÇÃO É PROTEÇÃO foi mantida em palavra, mas não completamente em metáfora nas duas traduções.(Tabela 4).

Da mesma forma que Jesus, o apóstolo Paulo também usa algumas metáforas e analogias ao escrever a seus seguidores. $\mathrm{Na}$ carta aos efésios, Paulo descreve as dificuldades espirituais pelas quais o cristão passa durante uma "guerra" ("porque a nossa luta não é contra o sangue e a carne, e sim [...] contra as forças espirituais do mal, nas regiões celestes", Ef. 6:12a). Ao classificá-la como metáfora estrutural (LAKOFF; JOHNSON, 2003), podemos dizer que faz parte da metáfora VIDA É GUERRA. Nessa guerra, os cristãos são os soldados, que enfrentam "ciladas" do diabo ("inimigo") (Ef. 6:11), e então há "combates" nas "batalhas", como Bunyan ilustra ao descrever uma luta entre Cristão e Apoliom (o “anjo do abismo" de Ap. 9:11).

20 Não faz parte de nossa proposta explicar detalhadamente todas as doutrinas cristãs. 
Tabela 4 - "Combate/batalha" - termos motivadores da metáfora

\section{Original}

I would, as the saying is, have given my life for a penny; but that, as God would have it, I was clothed with armour of proof. Ay, and yet, though I was so harnessed, I found it hard work to quit myself like a man. No man can tell what in that combat attends us, but he that hath been in the battle himself. (p. 154)

Tradução 1856

[...] então não podia ter tido esperança alguma de vida se não fosse revestido da armadura de Deos (Efesios 6. 13). Sim, e em despeito disto, custou-me. Ninguem pode dizer o que é combater com esses inimigos senão aquelle que tem-o experimentado. (Ed. 329)

Tradução 2006

Estive a ponto de, como diz o ditado, entregar a alma por um tostão, mas, graças a Deus, eu usava uma armadura reforçada. É... e mesmo protegido, achei difícil portar-me como homem. Só quem já experimentou essa batalha é capaz de dizer o que nos acontece nesse combate. (p. 170)

Fonte: Autores (2016)

$\mathrm{Na}$ tradução de 1856, a frase toda foi reformulada, citando-se o ato de "combater os inimigos", ignorando a parte referente à batalha, mas mantendo-se a primeira expressão. A tradução de 2006 inverte a ordem da frase; porém, mantém os mesmos termos "combate" e "batalha". Embora "batalha" esteja dentro da estrutura de guerra que a metáfora oferece, ela não foi traduzida por Kalley. Sendo assim, temos como resultado apenas uma metáfora cristalizada: combate.

Após nossa análise, podemos inferir de modo geral que a tradução de Robert Kalley (1856), por vezes, se aproximou do original, em expressão metafórica ou sentido metafórico, mas poucas vezes se igualou nos dois aspectos; diferente da tradução de Eduardo Ferreira (2006), em que a maioria se manteve em expressão e sentido. 
Segundo nosso entendimento, quando uma tradução de metáfora consegue manter tanto a expressão metafórica quanto o sentido metafórico, podemos dizer que houve manutenção total da metáfora e, quando apenas um dos aspectos, expressão ou sentido, é mantido, podemos dizer que houve manutenção parcial da metáfora.

\section{RESULTADOS}

Considerando as quatro metáforas analisadas e as maneiras como foram traduzidas, podemos constatar os seguintes direcionamentos dados pelos tradutores: 1. Manutenção total da metáfora - expressão e sentido mantidos, 2. Manutenção parcial da metáfora - expressão mantida/sentido não mantido, 3. Manutenção parcial da metáfora - expressão não mantida/ sentido mantido e 4. Omissão da metáfora.

$\mathrm{Na}$ tradução de Kalley (1856), houve apenas uma manutenção total da metáfora (“combat" - "combater"). Outras três resultaram em manutenção parcial das metáforas: uma manteve o sentido, mas não a expressão ("pilgrim" - "a viagem do Christão"); duas permaneceram com a mesma expressão, mas perderam o sentido metafórico do original ("burden" - "fardo"; "wall" - "muralha"); e uma resultou em omissão de metáfora ("battle”). Já Ferreira (2006), alcançou manutenção total de quatro metáforas ("pilgrim" - "peregrino"; "burden" - "fardo"; "combat" - "combate"; "battle" - "batalha"); e apenas uma resultou em manutenção parcial: não alcançou o sentido metafórico, por falta de inserção de versículos (tal qual no original) ("wall" - "muro").

Pudemos perceber que o tradutor de 1856 usou de liberdades em seu trabalho, a começar pelo próprio título $A$ viagem do Christão para a bemaventurança eterna. Supomos que, por ser conhecedor bíblico, Robert Kalley visava facilitar ou aproximar o leitor ao texto. Entretanto, ao fazê-lo, interferiu em possíveis implicaturas por parte do leitor (BAKER, 2001), por "interpretar" demais uma metáfora, como visto em “burden”. Já na tradução 
de 2006, ainda que Eduardo Ferreira não tenha usado todas as referências bíblicas, como o autor, é possível perceber que ele tenta, ao máximo, deixar o texto o mais próximo do original, usando quase todas as expressões, mantendo metáforas provenientes da bíblia o mais próximo de versões bastante utilizadas pelos protestantes.

\section{CONSIDERAÇÕES FINAIS}

Nossa análise, além de reiterar a importância de estudos acerca de metáforas empregadas no âmbito cristão e diferentes traduções, também ressalta sua relevância ao ensino de tradução, ao reforçar a ideia de que a atividade tradutória extrapola o aspecto meramente linguístico, sobretudo quando o tradutor tem que transpor expressões de linguagem para outra cultura, em que deve ler o "não-dito" e reescrevê-lo de tal forma que seu leitor entenda determinadas referências e, ainda assim, possa chegar a possíveis interpretações suscitadas pelo autor original, como preconizado por Baker (2001).

Este trabalho se encerra, mas fica aberta, para estudos futuros, a possibilidade de análise da tradução de mais literaturas do âmbito cristão, em especial, as que contenham metáforas bíblicas, uma vez que têm sido usadas há, pelo menos, dois mil anos e são traduzidas para tantas línguas e culturas diferentes.

\section{REFERÊNCIAS}

BAKER, M. Pragmatic equivalence. In: In other words: a coursebook on translation. New York: Taylor \& Francis, 2001. cap. 7, p. 217-260.

BÍBLIA ONLINE. Disponível em: <https://www.bibliaonline.com.br/akjv>. Acesso em: 14 out. 2016.

BÍBLIA. Português. Bíblia sagrada. Tradução: João Ferreira de Almeida. 2. ed. revista e atualizada. São Paulo: Sociedade Bíblica do Brasil, 2006.

BUNYAN, J. A viagem do Christão para a Bemaventurança Eterna. Tradução: Robert Reid Kalley. Correio Mercantil, Rio de Janeiro, 05 out. 1856 - 10 dez. 1856. Publicações a pedido. Disponível em: <http://bndigital.bn.br/ hemeroteca-digital/>. Acesso em: 12 mai. 2016. 
O Peregrino. Tradução: Eduardo Pereira e Ferreira. São Paulo: Mundo Cristão, 2006.

The Pilgrim's progress. London: J.M. Dent \& Sons, 1948.

CARDOSO, D. N. Robert Reid Kalley: médico, missionário e profeta. São Bernardo do Campo: Edição do autor, 2001.

CARDOSO, P. K. The Pilgrim's progress: análise de metáforas da caminhada cristã nas traduções de 1856 e 2006 para o português brasileiro. Orientador: Adauri Brezolin. 2016. 43p. Trabalho de conclusão de curso (Graduação) Universidade Metodista de São Paulo, São Bernardo do Campo, 2016.

DE LANGE, F. Life as a Pilgrimage: John Bunyan and the modern life course. In: Holtrop, P. H., Lange, F., Roukema, R. (ed.), Passion of Protestants, Kampen, 2004, p. 95-126. Disponível em: <http://home.kpn.nl/delangef/ pubbunyan.htm>. Acesso em: 22 set. 2016.

LAKOFF, G.; JOHNSON, M. Metaphors we live by. 2. ed. Chicago: The University of Chicago Press, 2003.

LATOURETTE, K. S. A Reforma na Inglaterra. In: Uma história do Cristianismo: volume II: 1.500 a.D. a 1975 a.D. Tradução: Herber Carlos de Campos. São Paulo: Hagnos, 2006. cap. 36, p. 1079-1131.

LEONEL, J. A formação do leitor protestante brasileiro em meados do século XIX: análise de O Peregrino. In: . História da literatura e protestantismo brasileiro. São Paulo: Universidade Presbiteriana Mackenzie e Paulinas Editora, 2000. cap. 2, p. 45-64.

MOISÉS, M. Dicionário de termos literários. 12.ed. São Paulo: Cultrix, 2004. Disponível em: <http://www.eduardoguerreirolosso.com/Massaud-Moises-Dicionario-de-Termos-Literarios.pdf>. Acesso em: 24 jul. 2017.

MOISÉS, M. Dicionário de termos literários. 12.ed. São Paulo: Cultrix, 2004.

SÉRGIO, R. A metáfora e suas ramificações. Recanto das Letras, 2013. Disponível em: <http://www.recantodasletras.com.br/gramatica/1162081>. Acesso em 10 out. 2016.

TENNEY, M. C. (Org.) Enciclopédia da Bíblia. 1 ed. São Paulo: Cultura Cristã, 2008. v. 5 .

\section{Os autores}

Adauri Brezolin: Doutor em Letras (USP); professor-titular do Curso de Letras, Língua Estrangeira, da Escola de Comunicação, Educação e Humanidades, da Universidade Metodista de São Paulo. adauri.brezolin@metodista.br

Priscila Klein Cardoso: Bacharel em Letras, Língua Estrangeira, da Escola de Comunicação, Educação e Humanidades, da Universidade Metodista de São Paulo. priscilaklein@gmail.com 